\title{
Fatty-Sucrosed Diet/Minimal Dose of Streptozotocin-Treated Rat: A Novel Model of Gestational Diabetes Mellitus, Metabolic and Inflammatory Insight
}

Eman S Abdel-Reheim, Adel Abd-Elmoneim A* and Ahmed A Hosni

Physiology Division, Zoology Department, Faculty of Science, Beni-Suef University, Egypt

\begin{abstract}
To date, a variety of experiments were done to get animal models of diabetes types. The current study is a trial to get a Gestational Diabetes Mellitus (GDM) model which is comparable to that in human, using a minimal dose of Streptozotocin (STZ). Female albino rats were divided into two groups; one fed Normal Diet (ND) and the other fed Fatty-Sucrosed Diet (FSD) from 60 days of age onward. After five weeks on the diets (pregestational period), rats were mated and STZ (25 mg/kg b.wt.) was injected intraperitoneally to FSD-fed dams at the $7^{\text {th }}$ day of gestation. During pregestational period, FSD-fed rats exhibited significant increase in body weight that reduced significantly after STZ injection in comparable to ND-fed rats. Frank hyperglycemia with mild decrease in serum insulin level of Gestational Diabetic (GD) dams showed a state of insulin resistance that clarified by the increase in Homeostasis Model Assessment Of Insulin Resistance (HOMA-IR) and subsequent decrease in Quantitative Insulin Sensitivity Check Index (QUICKI) values. Also, blood glycated hemoglobin (HbA1c) and fructosamine were significantly increased while hepatic glycogen content was decreased. In addition, lipid profile of GD-dams showed a significant increase in levels of Triglycerides (TG), total-cholesterol (Total-Ch.), LDL-cholesterol (LDL-Ch.) and vLDL-cholesterol (vLDLCh.) while HDL-cholesterol (HDL-Ch.) was decreased. Furthermore, serum adipokines levels showed a significant increase in leptin and tumor necrosis factor-alpha (TNF- $\alpha$ ) while adiponectin level was significantly decreased. On the other hand, the diabetic dams exhibited high rate of implantation loss and impaired fetal glycaemia. In conclusion the combination of FSD and a minimal dose of STZ can effectively induce gestational diabetes analogue to that of human and suitable for further investigations of physiological and molecular abnormalities in GDM.
\end{abstract}

Keywords: Fatty-sucrosed diet; Streptozotocin; Gestational diabetes; Insulin resistance; Adipokines; Rat model

\section{Introduction}

Diabetes mellitus is a multi-systemic disorder, affects almost every cell in the body and considered one of the most important health problems worldwide [1,2]. As the global epidemic of diabetes continues to expand, the prevalence of Gestational Diabetes Mellitus (GDM) increased from $1.4 \%$ to $25.5 \%$ over the last twenty years [3].

Gestational Diabetes Mellitus (GDM) is defined as any degree of glucose intolerance with onset or first recognition during pregnancy, irrespective of the glycemic status after delivery [4]. Insulin resistance and inadequate insulin secretion founded to play a central role in the pathophysiology of GDM [5]. Gestational diabetic women have increased risk of Type 2 Diabetes Mellitus (T2DM) and heart disease later in life [6], and their offspring have greater incidence of perinatal complications and increased risk of obesity and diabetes in adulthood [7].

Several models were developed to study gestational diabetes. The preferred and most often used experimental models are on rodents because of their convenient maintenance, short length of pregnancy, multiparty (enabling studies on multiple fetuses and generations), and lack of special problems in termination of pregnancy and fetus recovery [8]. GD-models include the genetic altered obese rats, high fat feeding rats and Streptozotocin (STZ) induced gestational diabetes, but these models do not reflect the metabolic characteristics of human GDM. However, the observations derived from the highly inbred genetic rat strains may not always be satisfactorily extended to the human population as a whole because of the large heterogeneity in the latter; these strains are expensive and are not easily available for the investigative purposes as well as regular screening experiments [9]. Moreover, the rats fed with High Fat Diet (HFD) develop obesity, hyperinsulinemia and insulin resistance but not cause frank hyperglycemia or diabetes, thus limiting the screening of agents on controlling the blood glucose level [10]. STZ-induced gestational diabetes either by a low $(30 \mathrm{mg} / \mathrm{kg})$ or high $(50 \mathrm{mg} / \mathrm{kg})$ dose of STZ on day one of gestation creates mild or severe maternal diabetes, respectively, resulting in direct pancreatic beta cell destruction and insulin deficiency rather than the consequence of insulin resistance, and causing various degrees of fetal resorption and malformed fetuses [11]. This aimed to study initiates an animal model that develops a suitable state closely mimic to the natural history (from insulin resistance to beta cell dysfunction) and metabolic features of human gestational diabetes.

\section{Materials and Methods}

\section{Animals}

Female virgin white albino rats (Rattus norvegicus) weighing about $100 \pm 10 \mathrm{~g}, 60$ day old, were used as experimental animals in this study. They were obtained from the animal house of Helwan town, Cairo, Egypt. The chosen animals were housed individually in standard polypropylene cages and maintained under normal atmospheric room temperature $\left(25 \pm 5^{\circ} \mathrm{C}\right)$, humidity $(55 \pm 5 \%)$, illumination $(12 \mathrm{~h}$ light $/ 12$

*Corresponding author: Adel Abd-Elmoneim A, Physiology Division, Zoology Department, Faculty of Science, Beni-Suef University, Salah Salim St., Egypt, Tel: +2 01006 5451764; Fax: +2 082233 4551; E-mail: adel men2020@yahoo.com

Received June 25, 2014; Accepted September 10, 2014; Published September 18,2014

Citation: Abdel-Reheim ES, Adel Abd-Elmoneim A, Hosni AA (2014) FattySucrosed Diet/Minimal Dose of Streptozotocin-Treated Rat: A Novel Model of Gestational Diabetes Mellitus, Metabolic and Inflammatory Insight. J Diabetes Metab 5: 430 doi:10.4172/2155-6156.1000430

Copyright: (C) 2014 Abdel-Reheim ES, et al. This is an open-access article distributed under the terms of the Creative Commons Attribution License, which permits unrestricted use, distribution, and reproduction in any medium, provided the original author and source are credited. 
$\mathrm{h}$ dark cycles) for one week before the onset of the experiment to be acclimatized. Rats had free access to water and to two dietary regimens.

\section{Dietary formula}

The rats were allocated into two dietary regimens by feeding either normal diet (ND; $60 \%$ starch, $5 \%$ corn oil and $20 \%$ casein protein as $\mathrm{g} \%$ ) or fatty-sucrosed diet (FSD; $25 \%$ sucrose, $40 \%$ beef tallow and $20 \%$ casein protein as $\mathrm{g} \%)$. Diet ingredients were purchased from Oxford Laboratories, Mumbai, India. Diets were prepared in the Department of Nutrition, Faculty of Veterinary Medicine, Beni-Suef University, BeniSuef, Egypt, at intervals according to requirements and stored at $4^{\circ} \mathrm{C}$ till use.

\section{Experimental design and animal grouping}

A total 40 rats were randomly assigned into two groups. ND group (received the normal diet) and FSD group (received fatty-sucrosed diet).

Five weeks after dietary manipulation, both groups were time mated overnight with males and the presence of sperms in the vaginal smear checked in the morning will be considered zero day of pregnancy. Female rats with negative detected sperms in the vaginal smear were excluded. Time before mating is referred to pre-gestational period while that after mating is referred to gestational period.

At the $7^{\text {th }}$ day of pregnancy FSD-feeding rats were fasted for 16 hours and then injected intraperitoneally (i.p.) with low dose of STZ (25 $\mathrm{mg} / \mathrm{kg}$ b.wt. in citrate buffer; $\mathrm{pH}$ 4.5) (preliminary study for the effect of other doses of STZ, 20, 30 and $35 \mathrm{mg} / \mathrm{kg}$, with FSD-feeding were performed). ND-feeding rats were i.p. injected only with the vehicle (citrate buffer; $\mathrm{pH} 4.5$ ). Glucose and insulin levels were evaluated on $6^{\text {th }}$ (pre-STZ), $13^{\text {th }}$ and $20^{\text {th }}$ (post-STZ) days of pregnancy. At the $21^{\text {st }}$ day of pregnancy, overnight fasted dams were sacrificed. Blood and tissues sampling and their all measured parameters were referred to main two groups $(\mathrm{n}=10$, each):

- NP + ND group: normal pregnant dams received normal diet.

- GD + FSD group: gestational diabetic dams received FSD/minimal dose of STZ (25 mg/kg b.wt.). Figure 1.

The experimental design and animal grouping is summarized in

\section{Blood sampling and tissue preparation}

Two blood samples were collected from each dam. The first was collected into a tube containing Ethylene Di-Amine Tetra-Acetic Acid

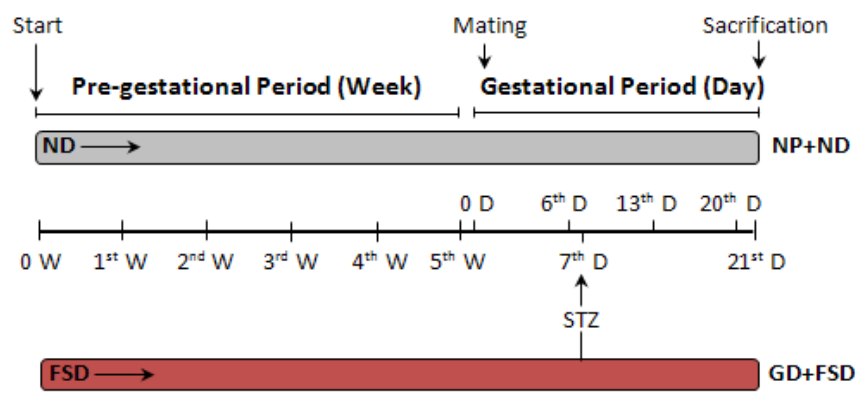

Figure 1: Experimental design and animal grouping. NP+ND: Normal pregnant dams received normal diet, GD+FSD: Gestational diabetic dams received fatty-sucrosed diet/minimal dose of streptozotocin (STZ; $25 \mathrm{mg} / \mathrm{kg}$ b.wt.).
(EDTA) as anticoagulant and used for determination of HbAlc. The second blood sample was allowed to coagulate, centrifuged and sera were kept at $-20^{\circ} \mathrm{C}$ for subsequent analysis. After dissection of the sacrificed rats, each dam uterine horns exposed to count fetus numbers and implantation loss sites. Fetuses were delivered and weighed. Fresh maternal liver samples were excised for determination of glycogen content. Blood pool was collected from the axillary vein of newborns of each dam and sera were separated for the immediate measurement of glucose and insulin.

\section{Food intake and body weight changes}

Food was provided in standard stainless steel hoppers. Food intake was calculated daily at the same time by subtracting the amount of food left over in the cage of each rat from the measured amount of food provided at the previous day. The mean of food consumption per each rat was considered by dividing the amount of food eaten in a week by 7 [12]. The average of food consumptions were represented in $\mathrm{g} /$ day/rat. Body weight for each rat was determined once a week $(\mathrm{g})$.

\section{Biochemical measurements}

Serum levels of glucose, fructosamine, triglycerides, totalcholesterol and HDL-cholesterol were determined using reagent kits obtained from Spinreact Company (Spain). Insulin was assayed in serum by Sandwich ELISA method using reagent kit purchased from BioSource Europe S.A. (Belgium), while serum leptin, TNF- $\alpha$ and adiponectin were estimated using reagent kits procured from RayBiotech, Inc. (USA). Because abnormalities in insulin action are poorly detected by a single determination of glucose or insulin levels [13], the maternal glucose-insulin homeostasis state were described by calculating HOMA-IR [14] and QUICKI [15]. HbA1c was determined using reagent kit purchased from BioSystems S.A. (Spain). Also, hepatic glycogen content was detected [16]. Serum LDL-cholesterol, vLDL-Cholesterol, Cardiovascular Risks (CVR1 \& CVR2) and AntiAtherogenic Index (AAI) were estimated [17-20].

\section{Statistical analysis}

All results are expressed as the mean \pm SEM. Two-way Analysis of Variance (ANOVA) followed by Duncan's method for post-hoc analysis was performed to compare the data of maternal body weight, food intake, and serum glucose and insulin levels. Student's $t$ test was used for analyzing other parameters. All results were analyzed using Statistical Package for Social Science (SPSS) version 20 software with significance set at $\mathrm{P}<0.05$ [21].

\section{Results}

\section{Body weight and food intake changes}

A) During pre-gestational period (Tables $1 \mathrm{a}$ and $\mathrm{b}$ and Figures $2 \mathrm{~A}$ and B)

FSD-feeding rats showed an obvious increase in their body weight up to the $5^{\text {th }}$ weeks accompanied with marked decrease in the food intake onward as compared to ND-fed rats. Two-way ANOVA revealed significant effect of time, diet $(\mathrm{P}<0.001)$ and time-diet interaction $(\mathrm{P}<0.01)$ on the body weight. However, the effect of time and diet were insignificant on the food intake, their interaction depicted significant effect $(\mathrm{P}<0.001)$.

B) During gestational period (Tables $2 \mathrm{a}$ and $\mathrm{b}$ and Figure $3 \mathrm{~A}$ and $\mathrm{B}$ )

At the $6^{\text {th }}$ day, GD+FSD dams showed marked increase in their body weight when compared to the normal ones. This increase is no 


\begin{tabular}{|c|c|c|c|c|c|c|c|}
\hline \multirow{2}{*}{ Parameter } & \multirow{2}{*}{ Group } & \multicolumn{6}{|c|}{ Pre-gestational period (Time) } \\
\hline & & 0 week & $1^{\text {st }}$ week & $2^{\text {nd }}$ week & $3^{\text {rd }}$ week & $4^{\text {th }}$ week & $5^{\text {th }}$ week \\
\hline \multirow{2}{*}{$\begin{array}{l}\text { Body weight } \\
\text { (g) }\end{array}$} & ND & $115.66 \pm 3.64^{a}$ & $142.00 \pm 3.60^{b}$ & $155.21 \pm 4.17^{\mathrm{bc}}$ & $166.28 \pm 1.86^{\mathrm{cd}}$ & $176.91 \pm 4.47^{\text {def }}$ & $189.86 \pm 4.76^{e f}$ \\
\hline & FSD & $119.75 \pm 2.59^{a}$ & $160.41 \pm 3.68^{c}$ & $176.08 \pm 2.66^{\mathrm{de}}$ & $191.75 \pm 1.54^{\mathrm{fg}}$ & $205.58 \pm 1.76^{\text {gh }}$ & $214.06 \pm 1.41^{\mathrm{h}}$ \\
\hline \multirow{2}{*}{$\begin{array}{l}\text { Food intake } \\
\text { (g/day/rat) }\end{array}$} & ND & -- & $12.40 \pm 0.31^{\mathrm{a}}$ & $14.42 \pm 0.58^{\mathrm{abc}}$ & $14.53 \pm 0.34^{\mathrm{abc}}$ & $15.93 \pm 0.45^{\mathrm{bc}}$ & $16.17 \pm 0.62^{c}$ \\
\hline & FSD & -- & $16.65 \pm 0.23^{c}$ & $15.82 \pm 0.74^{\mathrm{bc}}$ & $14.47 \pm 0.47^{\mathrm{abc}}$ & $13.73 \pm 0.6^{\mathrm{ab}}$ & $12.72 \pm 0.28^{a}$ \\
\hline
\end{tabular}

Data shown as mean \pm SEM of six rats

For each parameter, values with the same superscript letter are similar (non-significant, $P>0.05$ ) whereas others aren't (significant, $P<0.05$ ). ND: Normal Diet-fed rats, FSD: Fatty Sucrosed Diet-fed rats.

Table 1(a): Body weight and food intake of female rats during pre-gestational period

\begin{tabular}{|c|c|c|c|}
\hline Parameter & & Effect of time & Effect of Diet \\
\hline \multirow{2}{*}{ Body weight } & F calculated & 178.046 & 118.601 \\
\cline { 2 - 4 } & P-value & $P<0.001$ & $P<0.001$ \\
\hline \multirow{2}{*}{ Food intake } & F calculated & 0.948 & 0.002 \\
\cline { 2 - 4 } & P-value & $P>0.05$ & $P>0.01$ \\
\hline
\end{tabular}

$P<0.001$ and $P<0.01$ show significant effects at $\alpha=0.001$ and $\alpha=0.01$, respectively, while $P>0.05$ is insignificant.

Table 1(b): Two-way ANOVA to test the effect of time (pre-gestational period), diet and their interaction on body weight and food intake of female rats.

(A)

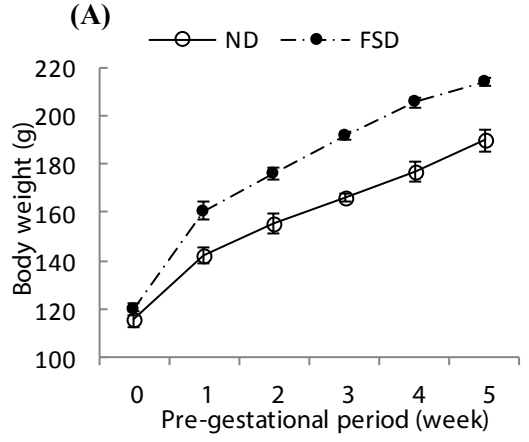

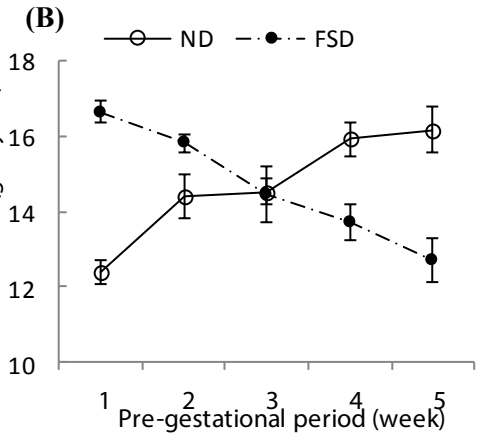

Figure 2: Body weight $(A)$ and food intake $(B)$ of female rats during pre-gestational period. FSD-feeding rats (closed circle) exhibited significant increase $(P<0.05)$ in the body weight with a significant decrease $(P<0.05)$ in their food intake than ND-feeding rats (open circle). Data shown as mean \pm SEM of six dams.

longer continuing after injection of STZ that cause obvious decrease in their body weight at the $13^{\text {th }}$ and the $20^{\text {th }}$ day of gestation as compared to NP+ND dams at the same periods. There was a non-notable change in food intake between both groups at the $6^{\text {th }}$ and the $13^{\text {th }}$ days, while it elevated at the end of the gestational period for GD+FSD dams. Twoway ANOVA analysis revealed significant effect $(\mathrm{P}<0.001)$ of time, diet and time-diet interaction on both of the body weight and food intake.

\section{Fasting and two hours (2hr) postprandial glucose level}

Dams of GD+FSD group showed elevation of fasting and $2 \mathrm{hr}$. postprandial glucose level at mid-gestation and late-gestation after streptozotocin injection at the dose of $25 \mathrm{mg} / \mathrm{kg}$ b.wt. Two-way ANOVA analysis revealed significant effect $(\mathrm{P}<0.001)$ of time, diet and time-diet interaction on both of serum fasting and $2 \mathrm{hr}$. glucose level (Tables $2 \mathrm{a}$ and $b$ and Figures $3 c$ and $d$ ).

However, the injection of STZ doses ( 35 and $30 \mathrm{mg} / \mathrm{kg}$ b.wt.) to FSD-fed dams at the $7^{\text {th }}$ day of gestation was found to produce a drastic reduction in their body weight, extremely elevated hyperglycemia and led finally to death. In contrast, the dose of STZ (20 mg/kg b.wt.) did not cause significant hyperglycemia in FSD-fed dams (data not shown).

\section{Fasting and two hours postprandial insulin level}

The recorded values in Tables $2 \mathrm{a}$ and $\mathrm{b}$ and Figure $3 \mathrm{e}$ and $\mathrm{f}$ indicated a significant increase in fasting and postprandial insulin level at early gestation (the $6^{\text {th }}$ day) in GD+FSD dams that turned to a notable decrease post-STZ injection in comparison to the control ones at mid and late gestation. Two-way ANOVA analysis revealed significant effect $(\mathrm{P}<0.001)$ of time, diet and time-diet interaction on both of serum fasting and $2 \mathrm{hr}$ insulin level.

\section{HOMA-IR and QUICKI indices}

Table 3 illustrated a significant increase $(\mathrm{P}<0.001)$ in HOMA-IR value of GD+FSD group accompanied with a significant decrease in QUICKI $(\mathrm{P}<0.001)$ as compared to normal pregnant group.

\section{HbA1c, Fructosamine and liver glycogen}

The recorded values of glycated hemoglobin $(\mathrm{HbAcl})$ and fructose amine showed a significant increase $(\mathrm{P}<0.001)$ in the gestational diabetic dams compared to the normal ones, while there was a significant decrease in the liver glycogen content values $(\mathrm{P}<0.001)$ showed in GD+FSD rats.

\section{The lipid profile and the cardiovascular indices}

The data describing the changes of lipid profile between GD+FSD and NP+ND groups clarify an overall significant increase $(\mathrm{P}<0.001)$ in triglyceride, total cholesterol, LDL-cholesterol and vLDL- cholesterol values, while HDL-cholesterol was significantly decreased $(\mathrm{P}<0.05)$ in the gestational diabetic rats. Cardiovascular risk index 1 and 2 exhibited the same behavioral pattern, where they were significantly increased 
Page 4 of 8

\begin{tabular}{|c|c|c|c|c|c|c|}
\hline \multirow{3}{*}{ Parameter } & \multirow{2}{*}{\multicolumn{3}{|c|}{$N P+N D$}} & \multicolumn{3}{|c|}{ GD+FSD } \\
\hline & & & & \multirow{2}{*}{$\begin{array}{c}\text { Pre-STZ } \\
6^{\text {th }} \text { day }\end{array}$} & \multicolumn{2}{|c|}{ Post-STZ } \\
\hline & $6^{\text {th }}$ day & $13^{\text {th }}$ day & $20^{\text {th }}$ day & & $13^{\text {th }}$ day & $20^{\text {th }}$ day \\
\hline Body weight (g) & $203.13 \pm 1.25^{\mathrm{a}}$ & $222.20 \pm 0.82^{c}$ & $241.38 \pm 1.14^{d}$ & $221.88 \pm 2.91^{c}$ & $209.60 \pm 2.38^{\mathrm{ab}}$ & $214.50 \pm 1.40^{\mathrm{bc}}$ \\
\hline $\begin{array}{l}\text { Food intake } \\
\text { (g/day/rat) }\end{array}$ & $14.78 \pm 0.37^{a}$ & $18.76 \pm 0.35^{b}$ & $23.16 \pm 0.42^{\mathrm{c}}$ & $12.30 \pm 0.36^{\mathrm{a}}$ & $18.81 \pm 0.45^{b}$ & $31.15 \pm 1.11^{\mathrm{d}}$ \\
\hline $\begin{array}{l}\text { Fasting glucose } \\
(\mathrm{mg} / \mathrm{dL})\end{array}$ & $82.70 \pm 1.64^{\mathrm{a}}$ & $76.08 \pm 3.34^{\mathrm{a}}$ & $64.70 \pm 2.11^{\mathrm{a}}$ & $122.54 \pm 1.54^{b}$ & $283.17 \pm 5.42^{\mathrm{c}}$ & $267.44 \pm 9.53^{c}$ \\
\hline $\begin{array}{l}\text { 2hr. glucose } \\
\text { (mg/dL) }\end{array}$ & $114.70 \pm 1.66^{b}$ & $102.62 \pm 1.50^{\mathrm{ab}}$ & $92.32 \pm 2.90^{\mathrm{a}}$ & $141.35 \pm 2.51^{c}$ & $372.00 \pm 3.84^{d}$ & $357.05 \pm 9.02^{\mathrm{d}}$ \\
\hline $\begin{array}{l}\text { Fasting insulin } \\
(\mu \mathrm{lU} / \mathrm{ml})\end{array}$ & $19.43 \pm 0.54^{\mathrm{b}}$ & $20.78 \pm 0.49^{\mathrm{bc}}$ & $27.12 \pm 0.91^{\mathrm{d}}$ & $23.12 \pm 0.35^{c}$ & $14.38 \pm 0.43^{\mathrm{a}}$ & $21.56 \pm 0.48^{b c}$ \\
\hline $\begin{array}{l}\text { 2hr. insulin } \\
(\mu \mathrm{lU} / \mathrm{ml})\end{array}$ & $22.30 \pm 0.28^{b}$ & $24.78 \pm 0.16^{c d}$ & $30.45 \pm 0.46^{\mathrm{e}}$ & $26.03 \pm 0.30^{d}$ & $18.71 \pm 0.4^{\mathrm{a}}$ & $24.25 \pm 0.24^{c}$ \\
\hline
\end{tabular}

Data shown as mean \pm SEM of six dams

For each parameter, values with the same superscript letter are similar (non-significant, $\mathrm{P}>0.05$ ) whereas others aren't (significant, $\mathrm{P}<0.05$ ). NP+ND: Normal pregnant dams received normal diet, GD+FSD: Gestational diabetic dams received fatty sucrosed diet/minimal dose of STZ (25 mg/kg b.wt.).

Table 2(a): Female rats body weight, food intake, and serum glucose and insulin levels during the gestational period.

\begin{tabular}{|c|c|c|c|c|}
\hline Parameter & & Effect of time & Effect of Diet & Time-Diet interaction \\
\hline \multirow[t]{2}{*}{ Body weight } & F calculated & 40.009 & 21.787 & 82.848 \\
\hline & P-value & $P<0.001$ & $P<0.001$ & $P<0.001$ \\
\hline \multirow{2}{*}{ Food intake } & F calculated & 276.893 & 15.070 & 43.765 \\
\hline & P-value & $P<0.001$ & $P<0.001$ & $P<0.001$ \\
\hline \multirow[t]{2}{*}{ Fasting glucose } & F calculated & 110.359 & 807.884 & 133.355 \\
\hline & P-value & $P<0.001$ & $P<0.001$ & $P<0.001$ \\
\hline \multirow{2}{*}{$2 \mathrm{hr}$. glucose } & F calculated & 959.571 & 5752.604 & 1165.918 \\
\hline & P-value & $\mathrm{P}<0.001$ & $\mathrm{P}<0.001$ & $P<0.001$ \\
\hline \multirow{2}{*}{ Fasting insulin } & F calculated & 72.777 & 36.086 & 49.719 \\
\hline & P-value & $P<0.001$ & $P<0.001$ & $P<0.001$ \\
\hline \multirow{2}{*}{$2 \mathrm{hr}$. insulin } & F calculated & 152.254 & 116.904 & 155.971 \\
\hline & P-value & $P<0.001$ & $P<0.001$ & $P<0.001$ \\
\hline
\end{tabular}

$P<0.001$ shows significant effect at $\alpha=0.001$

Table 2(b): Two-way ANOVA to test the effect of time (gestational period), diet and their interaction on body weight, food intake, and serum glucose and insulin levels of female rats.

$(\mathrm{P}<0.01)$ in gestational diabetic dams while the antiatherogeic index showed an opposite behavior.

\section{Leptin, TNF- $\alpha$ and adiponectin}

According to the data represented in Table 3, serum leptin and TNF- $\alpha$ were significantly increase $(\mathrm{P}<0.001)$ in the GD+FSD dams as compared to the normal ones. In contrast, adiponectin showed a significant decrease $(\mathrm{P}<0.001)$ in diabetic rats compared to $\mathrm{NP}+\mathrm{ND}$ ones.

\section{The maternal reproductive outcome and fetal glycemic state}

Table 4 indicated that the average number of lived fetuses was significantly decreased $(\mathrm{P}<0.05)$ in the gestational diabetic dams when compared to those of normal ones. In turn the implantation loss sites of diabetic dams showed a significant increase $(\mathrm{P}<0.01)$. The fetal weight recorded in the same table indicated a significant increase $(\mathrm{P}<0.05)$ in the fetuses of GD+FSD rats. Corresponding the fetal glucose and insulin concentrations of both groups, there were an obvious significant increase $(\mathrm{P}<0.001)$ in these parameters for $\mathrm{GD}+\mathrm{FSD}$-fetuses in comparison to those of normal ones.

\section{Discussion}

As mentioned, several animal models were developed to study gestational diabetes but the pattern of disease initiation and development in most of them do not appear to be closely analogous to the clinical situation in humans. High Fat Diet (HFD)-fed with low dose of Streptozotocin (STZ)-treated rat is a well-known model used to develop type II diabetes [22]. Our studies modify this model to initiate a novel rat model that mimics the pathophysiology of human gestational diabetes and more sensitive to the pharmacological testing. FSD-feeding, that results in insulin resistance through glucose-fatty acid cycle [23], and injection of a very low dose of STZ (25 mg/kg b.wt.) at the $7^{\text {th }}$ day of gestation, that makes partial dysfunction of maternal beta cells with a low percentage of fetal malformations [24], founded to be suitable for this purpose.

In view of our results, the pregestational period showed a significant increase in body weight of dams fed FSD. Consumption of this diet facilitates the development of a positive energy balance leading to an increase in visceral fat deposition [25]. The increase in body weight was accompanied with a significant decrease in the food intake that might be due to the elevated plasma leptin level which set the received calorie by the rats.

During gestational period and post-STZ injection, gestational diabetic dams indicate marked decrease in their body weights. The given low dose of STZ causes moderate destruction of pancreatic $\beta$-cells. Together, with FSD-feeding, caused impairment in glucose stimulated insulin release and insulin resistance [26] that divert the body toward the catabolism of fats and proteins resulting in body weight loss [27]. It is relevant here to mention that dams of both groups showed fluctuating increase in their body weight at the $20^{\text {th }}$ day of gestation as a result of the complete development of their fetuses and the probable labor during the next day. 

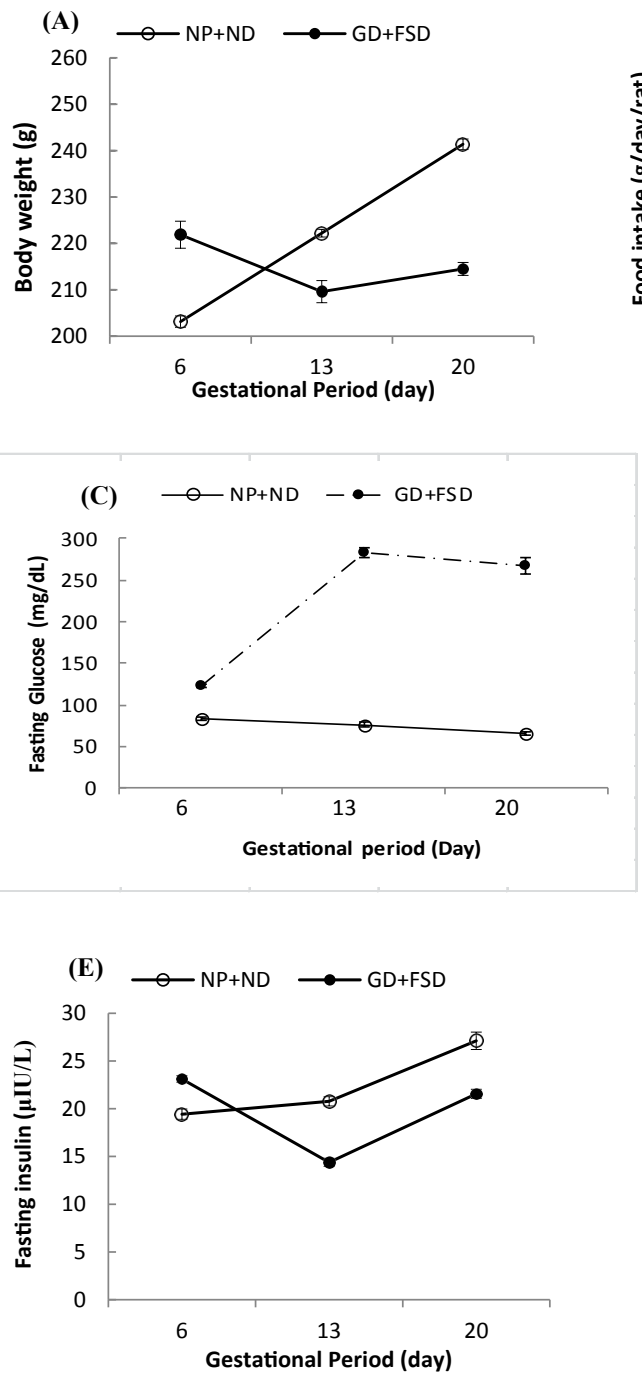
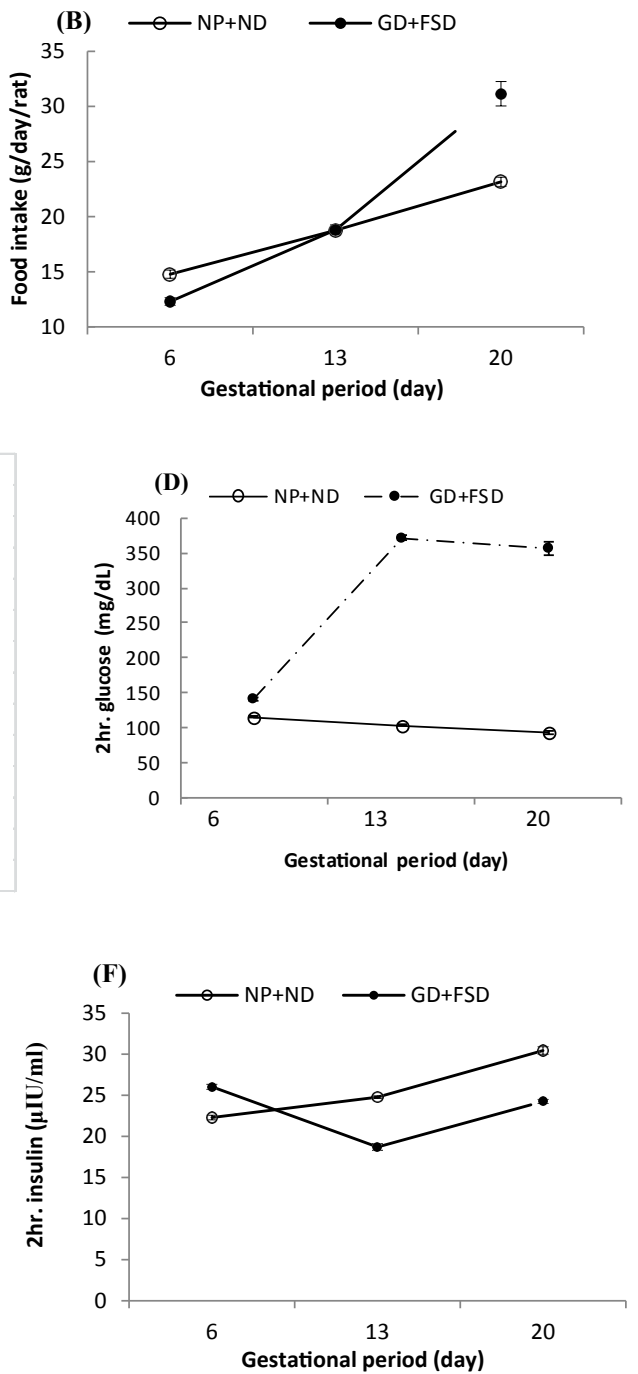

Figure 3: Body weight (A), food intake (B), and serum fasting glucose (C), 2 hours postprandial glucose (D), fasting insulin (E) and 2 hours postprandial insulin levels $(F)$ of female rats during the gestational period. Data shown as mean \pm SEM of six dams. NP+ND: Normal pregnant dams received normal diet, GD+FSD: Gestational diabetic dams received fatty sucrosed diet/minimal dose of STZ ( $25 \mathrm{mg} / \mathrm{kg}$ b.wt.). GD+FSD group (closed circle) exhibited significant increase (P<0.05) in the food intake and serum glucose level while it have a significant decrease $(P<0.05)$ in their body weight and serum insulin level as compared to NP+ND group.

The hyperglycemia observed in the gestational diabetic dams could be due to a state of insulin resistance, confirmed by the elevation of HOMA-IR value that accompanied with a decrease in QUICKI level, and the injection of a minimal dose of STZ.

The observed insulin resistance state may be a result of feeding of FSD and the hormonal production of placenta. FSD-feeding founded to increase serum Free Fatty Acids (FFAs) level that plays a key role in promoting loss of insulin sensitivity by increasing serine phosphorylation of insulin receptor (IR) at the expense of its tyrosine phosphorylation causing reduction in the Glucose Transporter-4 (GLUT4) translocation to the plasma membrane and the consequent decrease in the peripheral tissue glucose utilization $[28,29]$. At the same level, Placental Growth Hormone (PGH) and Placental Lactogen (PL) are the two main placental hormones that implicated in the state of insulin resistance, where they attenuating phosphatidylinisitol 3-kinase (PI 3-kinase) activation which led to depression in translocation of GLUT4 and the resultant decrease in insulin-stimulated glucose uptake to skeletal muscle [30]. Moreover, PL stimulates lipolysis leading to an increase in circulating free fatty acids that interferes with insulindirected entry of glucose into cells. Therefore, PL is considered as a potent antagonist to insulin action during pregnancy [31].

Injection of STZ selectively destructs $\beta$-cells of the islets of Langerhans in the pancreas [32]. The cytotoxic action of STZ is associated with its deoxyglucose moiety that facilitates the transport across the cell membrane of the pancreatic $\beta$-cells via glucose transporter-2, and with its DNA alkylating activity through methylnitrosourea moiety; where the transfer of the methyl group from streptozotocin to the DNA molecule causes its fragmentation. STZ, also, increases the Reactive Oxygen Species (ROS) generation and inhibits the free radical scavenger-enzymes enhancing the pancreatic $\beta$-cells destruction [33].

Marked alterations in lipid metabolism have been reported in the gestational diabetes [34]. The observed hypertriglyceridemia and hypercholesterolemia may be due to increased dietary triglycerides and cholesterol absorption from the small intestine following the 


\begin{tabular}{|c|c|c|}
\hline Parameter & NP+ND & GD+FSD \\
\hline HOMA-IR [[(Fasting Insulin, $\mu \mathrm{IU} / \mathrm{ml}) \times($ Fasting Glucose, $\mathrm{mmol} / \mathrm{L})] / 22.5]$ & $4.27 \pm 0.15$ & $25.50 \pm 0.51^{*}$ \\
\hline QUICKI [1/ [Log (Fasting Insulin, $\mu \mathrm{IU} / \mathrm{ml})+$ Log (Fasting Glucose, mg/dL)]] & $0.31 \pm 0.001$ & $0.25 \pm 0.001^{*}$ \\
\hline $\mathrm{HbA1c}(\%)$ & $4.87 \pm 0.12$ & $6.86 \pm 0.08^{\star}$ \\
\hline Fructosamine (mmol/L) & $45.39 \pm 3.05$ & $185.70 \pm 5.25^{*}$ \\
\hline Liver glycogen content (mg/g tissue) & $12.69 \pm 0.57$ & $3.55 \pm 0.19^{*}$ \\
\hline Triglycerides (mg/dL) & $58.72 \pm 1.44$ & $189.64 \pm 1.34^{*}$ \\
\hline Total Cholesterol (mg/dL) & $81.12 \pm 1.45$ & $185.13 \pm 2.51^{*}$ \\
\hline HDL-Ch.(mg/dL) & $58.06 \pm 1.54$ & $52.52 \pm 1.18^{\#}$ \\
\hline LDL-Ch. (mg/dL) [Total-Ch - T.G/5 - HDL-Ch.] & $11.95 \pm 0.51$ & $94.59 \pm 2.74^{*}$ \\
\hline vLDL-Ch. (mg/dL) [T.G./5] & $11.74 \pm 0.29$ & $37.93 \pm 0.26^{*}$ \\
\hline CVR1 [Total-Ch./HDL-Ch.] & $1.37 \pm 0.05$ & $3.53 \pm 0.09^{*}$ \\
\hline CVR2 [LDL-Ch./HDL-Ch.] & $0.20 \pm 0.01$ & $1.80 \pm 0.08^{*}$ \\
\hline AAI [HDL-Ch. ×100 / Total Ch. - HDL-Ch.] & $290.85 \pm 20.96$ & $40.19 \pm 1.47^{*}$ \\
\hline Leptin (pg/ml) & $574.65 \pm 46.38$ & $1265.40 \pm 42.15^{\star}$ \\
\hline TNF- $\alpha(p g / m l)$ & $210.77 \pm 4.42$ & $374.40 \pm 7.19^{*}$ \\
\hline Adiponectin (pg/ml) & $946.68 \pm 4.54$ & $693.95 \pm 16.73^{*}$ \\
\hline
\end{tabular}

Data shown as mean \pm SEM of six dams

${ }^{\#} \mathrm{P}<0.05,{ }^{*} \mathrm{P}<0.001$ versus NP+ND group NP+ND: Normal pregnant dams received normal diet, GD+FSD: Gestational diabetic dams received fatty sucrosed diet/minimal dose of STZ (25 mg/kg b.wt.).

Table 3: Maternal glucose-insulin homeostasis, lipid profile and adipocytokines of NP+ND and GD+FSD after scarification

\begin{tabular}{|c|c|c|}
\hline Parameter & NP+ND & GD+FSD \\
\hline Live fetuses & $8.75 \pm 0.52$ & $4.25 \pm 0.22^{\#}$ \\
\hline Implantation loss & $3.50 \pm 0.2$ & $9.50 \pm 0.38^{i}$ \\
\hline Fetal weight $(\mathrm{g})$ & $3.08 \pm 0.03$ & $3.40 \pm 0.10^{\#}$ \\
\hline Fetal glucose $(\mathrm{mg} / \mathrm{dL})$ & $24.94 \pm 1.46$ & $161.50 \pm 4.12^{*}$ \\
\hline Fetal insulin $(\mu \mathrm{lU} / \mathrm{ml})$ & $3.60 \pm 0.14$ & $6.20 \pm 0.16^{*}$ \\
\hline
\end{tabular}

Data shown as mean \pm SEM of six dams ${ }^{\#} P<0.05$, iP $<0.01$, ${ }^{*} P<0.001$ versus NP+ND group NP+ND: Normal pregnant dams received normal diet, GD+FSD: Gestational diabetic dams received fatty sucrosed diet/minimal dose of STZ (25 mg/kg b.wt.).

Table 4: Maternal reproductive outcome, and fetal glucose and insulin levels.

intake of FSD, decreased T.G. uptake in peripheral tissues as a result of dysfunction of insulin-dependent Lipoprotein Lipase (LPL), increased hepatic production of triglycerides enriched very Low Density Lipoprotein (vLDL-TG) or through activation of hepatic 3-hydroxy3-methylglutaryl coenzyme A (HMG-CoA) reductase, which is a rate limiting enzyme involved in cholesterol synthesis $[10,35,36]$

Adipose tissue is an active participant in controlling the pathophysiology of GDM by releasing a variety of adipokines in the blood stream that are directly or indirectly involved in the state of insulin resistance accompanied GDM [37]. Our study revealed a significant increase in both serum leptin and TNF- $\alpha$ level in GD+FSD group. These findings are in agree with who stated that these adipokines were significantly high in gestational diabetic mothers and are conversely correlated with insulin secretion and sensitivity [38]. On the other hand, hypoadiponectinemia was reported in the diabetic group that illustrates the severe state of insulin resistance [39]. Leptin, an antiobesity adipocyte-derived hormone, is supposed to regulate body weight through a negative feedback signal between adipose tissue and the hypothalamic satiety center causing a decrease in food intake and an increase in energy expenditure [40]. The elevated leptin concentrations may actually represent a state of leptin resistance. Hyperleptinemia proved to cause insulin resistance through impairment of tyrosine phosphorylation of IR, increasing peroxynitrite-mediated oxidative stress and stimulation of T-helper cell proliferation that control release of the most important proinflammatory cytokine TNF- $\alpha$ [41-43]. TNF- $\alpha$ is thought to induce insulin resistance by number of mechanisms involving the increase in serine phosphorylation of the Insulin Receptor Substrate-1 (IRS-1) that impaired the insulin- signaling cascade, and mediating lipolysis through suppression of the peroxisome proliferated activated receptor- $\gamma$ (PPAR- $\gamma$ ) expression in adipose tissues that is essential in fat cell differentiation and lipid storage $[44,45]$. In contrast to other adipokines, adiponectin has insulin sensitizing effect which is attributed primarily to decreasing expression of gluconeogenic enzymes (as phosphoenolpyruvate carboxykinase and glucose-6-phosphatase) which in turn suppress the hepatic glucose production and enhancing fatty acid oxidation and energy dissipation causing decrease in tissue T.G. accumulation and increase in insulin sensitivity $[46,47]$.

Regarding the offspring, the maternal glucose intolerance showed in GD+FSD dams as a result of FSD-feeding not prevent embryo implantation. Elsewhere, injection of STZ at the $7^{\text {th }}$ day of gestation revealed higher implantation loss sites in these dams as compared to normal ones. This result confirmed by the decrease in the number of live fetuses that may be attributed to intrauterine growth restriction [48]. As placental transfer of glucose is carried out by facilitated diffusion according to concentration-dependent kinetics, fetuses of FSD+GDrats showed high glycaemia level accompanied by fetal hyperinsulinism $[11,49]$. It is known that insulin is one of the main growth factors during fetal life, thus the hyperinsulinemia leads to macrosomia [50].

\section{Conclusion}

The present model proved that the combination of fatty-sucrosed diet and the minimal dose of streptozotocin serve as alternative model for GDM study and is suitable for testing different maternal pathophysiological alterations and the attributed fetal development errors. 
Citation: Abdel-Reheim ES, Adel Abd-Elmoneim A, Hosni AA (2014) Fatty-Sucrosed Diet/Minimal Dose of Streptozotocin-Treated Rat: A Novel Model of Gestational Diabetes Mellitus, Metabolic and Inflammatory Insight. J Diabetes Metab 5: 430 doi:10.4172/2155-6156.1000430

\section{Acknowledgement}

The authors are grateful to BSU-research center, Beni-suef University, Egypt for providing the research grant.

\section{References}

1. Gupta R, Bajpai KG, Johri S, Saxena A (2008) An overview of Indian nove traditional medicinal plants with anti-diabetic potentials. African Journal of Traditional, Complementary, and Alternative Medicines 5: 1-17.

2. Manna P, Das J, Ghosh J, Sil PC (2010) Contribution of type 1 diabetes to rat liver dysfunction and cellular damage via activation of NOS, PPAR, IkBa/ NF-kB, MAPKs, and mitochondria-dependent pathway: Prophylactic role of arjunolic acid. Free Radical Biology and Medicine 48: 1465-1484.

3. Sacks DA, Hadden DR, Maresh M, Deerochanawong C, Dyer AR, et al. (2012) Frequency of gestational diabetes mellitus at collaborating centers based on IADPSG consensus panel-recommended criteria: the Hyperglycemia and Adverse Pregnancy Outcome (HAPO) Study. Diabetes Care 35: 526-528.

4. Wendland EM, Torloni MR, Falavigna M, Trujillo J, Dode MA, et al. (2012) Gestational diabetes and pregnancy outcomes-a systematic review of the World Health Organization (WHO) and the International Association of Diabetes in Pregnancy Study Groups (IADPSG) diagnostic criteria. BMC Pregnancy and Childbirth 12: 23

5. Buchanan TA, Xiang AH, Page KA (2012) Gestational diabetes mellitus: risks and management during and after pregnancy. Nat Rev Endocrinol 8: 639-649.

6. Lee H, Jang HC, Park HK, Metzger BE, Cho NH (2008) Prevalence of type 2 diabetes among women with a previous history of gestational diabetes mellitus. Diabetes Res Clin Pract 81: 124-129.

7. Metzger BE (2007) Long-term outcomes in mothers diagnosed with gestationa diabetes mellitus and their offspring. Clin Obstet Gynecol 50: 972-979.

8. Shafrir E, Desoye G (2003) Pregnancy in diabetic animals. Hod M, Jovanovic L, Di Renzo GC, Leiva A, Langer O. Textbook of diabetes and pregnancy. United Kingdon, Informa UK Ltd 96-97.

9. Shafrir E (2003) Diabetes in animals: Contribution to the understanding of diabetes by study of its etiopathology in animal models. In: Porte D, Sherwin RS, Baron A editors. Diabetes mellitus. NewYork, McGraw-Hill 231-255.

10. Srinivasan K, Patole PS, Kaul CL, Ramarao P (2004) Reversal of glucose intolerance by by pioglitazone in high fat diet-fed rats. Methods Find Exp Clin Pharmacol 26: 327-333.

11. Caluwaerts S, Holemans K, van Bree R, Verhaeghe J, Van Assche FA (2003) Is low-dose streptozotocin in rats an adequate model for gestational diabetes mellitus? J Soc Gynecol Investig 10: 216-221.

12. Amin KA, Nagy MA (2009) Effect of Carnitine and herbal mixture extract on obesity induced by high fat diet in rats. Diabetol Metab Syndr 1: 17.

13. Consensus Development Conference on Insulin Resistance. 5-6 November 1997. American Diabetes Association. Diabetes Care 21: 310-314.

14. Matthews DR, Hosker JP, Rudenski AS, Naylor BA, Treacher DF, et al. (1985) Homeostasis model assessment: insulin resistance and beta-cell function from fasting plasma glucose and insulin concentrations in man. Diabetologia 28 $412-419$

15. Katz A, Nambi SS, Mather K, Baron AD, Follmann DA, et al. (2000) Quantitative insulin sensitivity check index: a simple, accurate method for assessing insulin sensitivity in humans. Journal of Clinical Endocrinology \& Metabolism 85: 2402 2410.

16. SEIFTER S, DAYTON S, et al (1950) The estimation of glycogen with the anthrone reagent. Arch Biochem 25: 191-200.

17. Friedewald WT, Levy RI, Fredrickson DS (1972) Estimation of the concentration of low-density lipoprotein cholesterol in plasma, without use of the preparative ultracentrifuge. Clin Chem 18: 499-502.

18. Nobert WT (1995) Clinical guide to laboratory tests. 3rd edn, W.B. Saunders Company, Philadilphia.

19. Ross $R$ (1992) The pathogenesis of atherosclerosis. In heart disease, 4th edn Edited by Braunwald, E.Philadelphia, WB Saunders 1106-1124.

20. Guido S, Joseph T (1992) Effect of chemically different calcium antagonists on lipid profile in rats fed on a high fat diet. Indian J Exp Biol 30: 292-294.
21. IBM Corp (2011) IBM SPSS Statistics for Windows, Version 20.0. Armonk, NY.

22. Srinivasan K1, Viswanad B, Asrat L, Kaul CL, Ramarao P (2005) Combination of high-fat diet-fed and low-dose streptozotocin-treated rat: a model for type 2 diabetes and pharmacological screening. Pharmacol Res 52: 313-320.

23. Zhang F1, Ye C, Li G, Ding W, Zhou W, et al. (2003) The rat model of type 2 diabetic mellitus and its glycometabolism characters. Exp Anim 52: 401-407.

24. López-Soldado 11, Herrera E (2003) Different diabetogenic response to moderate doses of streptozotocin in pregnant rats, and its long-term consequences in the offspring. Exp Diabesity Res 4: 107-118.

25. Farrokhi B, Ghalami J, Hedayati M, Rostamkhani F, Zardooz H (2011) High-fat diet did not change metabolic response to acute stress in rats. EXCLI J 10 205-217.

26. Farswan M, Mazumder PM, Parcha V (2009) Modulatory effect of isolated compound from Syzyium cumini seeds on biochemical parameters of diabetes in rats. Int J Green Pharm 3: 128-33.

27. Chatterjea MN, Shinde R (2002) Textbook of Medical Biochemistry. Jaypee Brothers, Medical Publishers Pvt. Ltd, New Delhi 317.

28. Turcotte LP1, Fisher JS (2008) Skeletal muscle insulin resistance: roles of fatty acid metabolism and exercise. Phys Ther 88: 1279-1296.

29. Schaefer-Graf U, Meitzner K, Ortega-Senovilla H, Graf K, Vetter K, et al. (2011) Differences in the implications of maternal lipids on fetal metabolism and growth between gestational diabetes mellitus and control pregnancies. Diabetic medicine 28: 1053-1059.

30. Barbour LA, Shao J, Qiao L, Leitner W, Anderson M, et al. (2004) Human placental growth hormone increases expression of the p85 regulatory unit of phosphatidylinositol 3-kinase and triggers severe insulin resistance in skeletal muscle. Endocrinology 145: 1144-1150.

31. Al-Noaemi MC, Shalayel MH (2011) Pathophysiology of Gestational Diabetes Mellitus: The Past, the Present and the Future, Gestational Diabetes, Miroslav Radenkovic (edn.)

32. Lenzen S (2008) The mechanisms of alloxan- and streptozotocin-induced diabetes. Diabetologia 51: 216-226.

33. Zhang W, Zhao J, Wang J, Pang X, Zhuang X, et al. (2010) Hypoglycemic effect of aqueous extract of seabuckthorn (Hippophae rhamnoides L.) seed residues in streptozotocin-induced diabetic rats. Phytother Res 24: 228-232.

34. Herrera E, Ortega-Senovilla H (2010) Disturbances in lipid metabolism in diabetic pregnancy - Are these the cause of the problem? Best Pract Res Clin Endocrinol Metab 24: 515-525.

35. Raz I, Eldor R, Cernea S, Shafrir E (2005) Diabetes: insulin resistance and derangements in lipid metabolism. Cure through intervention in fat transport and storage. Diabetes Metab Res Rev 21: 3-14.

36. Shah SS, Shah GB, Singh SD, Gohil PV, Chauhan K, et al. (2011) Effect of piperine in the regulation of obesity-induced dyslipidemia in high-fat diet rats. Indian J Pharmacol 43: 296-299.

37. Catalano PM (2010) Obesity, insulin resistance, and pregnancy outcome Reproduction 140: 365-371.

38. Metzger BE, Buchanan TA, Coustan DR, de Leiva A, Dunger DB, et al (2007) Summary and recommendations of the Fifth International WorkshopConference on Gestational Diabetes Mellitus. Diabetes Care 30 Suppl 2 S251-260.

39. Ranheim T, Haugen F, Staff AC, Braekke K, Harsem NK, et al. (2004) Adiponectin is reduced in gestational diabetes mellitus in normal weight women. Acta Obstet Gynecol Scand 83: 341-347.

40. Morrison CD, Huypens P, Stewart LK, Gettys TW (2009) Implications of crosstalk between leptin and insulin signaling during the development of dietinduced obesity. Biochim Biophys Acta 1792: 409-416.

41. Pérez $C$, Fernández-Galaz $C$, Fernández-Agulló T, Arribas $C$, Andrés $A$, et al (2004) Leptin impairs insulin signaling in rat adipocytes. Diabetes 53: 347-353.

42. Chatterjee S, Ganini D, Tokar EJ, Kumar A, Das S, et al. (2013) Leptin is key to peroxynitrite-mediated oxidative stress and Kupffer cell activation in experimental non-alcoholic steatohepatitis. J Hepatol 58: 778-784.

43. Fernández-Riejos $P$, Najib S, Santos-Alvarez J, Martín-Romero C, Pérez-Pérez A, et al. (2010) Role of leptin in the activation of immune cells. Mediators Inflamm 2010: 568343. 
Citation: Abdel-Reheim ES, Adel Abd-Elmoneim A, Hosni AA (2014) Fatty-Sucrosed Diet/Minimal Dose of Streptozotocin-Treated Rat: A Novel Model of Gestational Diabetes Mellitus, Metabolic and Inflammatory Insight. J Diabetes Metab 5: 430 doi:10.4172/2155-6156.1000430

Page 8 of 8

44. Rui L, Aguirre V, Kim JK, Shulman GI, Lee A, et al. (2001) Insulin/IGF-1 and TNF-alpha stimulate phosphorylation of IRS-1 at inhibitory Ser307 via distinct pathways. J Clin Invest 107: 181-189.

45. Joosen AM, Bakker AH, Zorenc AH, Kersten S, Schrauwen P, et al. (2006) PPARgamma activity in subcutaneous abdominal fat tissue and fat mass gain during short-term overfeeding. Int J Obes (Lond) 30: 302-307.

46. Yamauchi T, Kamon J, Minokoshi Y, Ito Y, Waki H, et al. (2002) Adiponectin stimulates glucose utilization and fatty-acid oxidation by activating AMPactivated protein kinase. Nat Med 8: 1288-1295

47. Tomas E, Tsao TS, Saha AK, Murrey HE, cheng Zhang C, et al. (2002) Enhanced muscle fat oxidation and glucose transport by ACRP30 globular domain: Acetyl-CoA carboxylase inhibition and AMP-activated protein kinase activation. Proceedings of the National Academy of Sciences 99: 16309-16313.
48. Aerts L, Van Assche FA (2006) Animal evidence for the transgenerational development of diabetes mellitus. Int J Biochem Cell Biol 38: 894-903.

49. Day PE, Cleal JK, Lofthouse EM, Hanson MA, Lewis RM (2013) What factors determine placental glucose transfer kinetics? Placenta 34: 953-958.

50. Schwartz R, Gruppuso PA, Petzold K, Brambilla D, Hiilesmaa V, et al. (1994) Hyperinsulinemia and macrosomia in the fetus of the diabetic mother. Diabetes Care 17: 640-648. 